\title{
Análise dos Stakeholders e Gestão dos Meios de Hospedagem: estudo de casos múltiplos na Vila do Abraão, Ilha Grande, $\mathbf{R J}^{\mathbf{1}}$
}

\author{
Stakeholder Analysis and Management of Lodging Ventures: multiple case study in the \\ Vila do Abrã̃o, Ilha Grande, RJ, Brazil
}

\section{Análisis de los Stakeholders y Gestión de Alojamientos: estudio de casos múltiplos en la Vila do Abraão, Ilha Grande, RJ, Brasil}

Erika Sayuri Koga ${ }^{2}$

Elizabeth Kyoko Wada ${ }^{3}$

\begin{abstract}
Resumo
Verificar o envolvimento dos meios de hospedagem com os grupos que influenciam ou podem influenciar uma organização, os chamados stakeholders, pode aprimorar as conexões entre empreendimentos, instituições e pessoas em um destino turístico. Esta pesquisa tem como objetivo diagnosticar as relações existentes entre os meios de hospedagem e os stakeholders para o desenvolvimento turístico da localidade. Como objetivos específicos, visa hierarquizar o nível de importância de cada stakeholder para o sucesso dos negócios e identificar as formas de integração dos meios de hospedagem e os stakeholders na Vila do Abraão, Ilha Grande. O artigo é resultado da dissertação de mestrado. Consistiu em estudo exploratório com caráter qualitativo e estudo de casos múltiplos dos meios de hospedagem na Vila do Abraão, localizada na Ilha Grande, Rio de Janeiro. Efetuou-se levantamento bibliográfico sobre gestão empresarial, tomando a obra de Freeman (1984) como marco referencial. Identificaram-se nove stakeholders que influenciam a gestão dos meios de hospedagem. Os grupos identificados têm níveis diferentes de importância para o sucesso dos negócios, verificando que os clientes e a mídia são os stakeholders com maior nível de influência. As relações existentes de cooperação são escassas e falta gestão dos empreendimentos para aprimorar as conexões com os stakeholders.
\end{abstract}

Palavras-chave: turismo; hospitalidade; stakeholders; meios de hospedagem; Ilha Grande.

\footnotetext{
Abstract

${ }^{1}$ Agradecimento a CAPES pelo apoio à pesquisa, através de bolsa científica.

${ }^{2}$ Mestre em Hospitalidade pela Universidade Anhembi Morumbi; Pós-Graduada MBA de Gestão Empresarial pela Fundação Getúlio Vargas; Professora do Curso de Bacharelado em Hotelaria do Senac-SP. Brasil. E-mail: kogadinapoli@gmail.com.

${ }^{3}$ Doutora e Mestre em Ciências da Comunicação pela Universidade de São Paulo; diretora de Pós-Graduação Stricto Sensu, Coordenadora do Programa de Mestrado em Hospitalidade e Diretora da Escola de Turismo e Hospitalidade da Universidade Anhembi Morumbi. Brasil. E-mail: ewada@uol.com.br.
} 
Verify the involvement of the lodging sector with the various groups that influence or can influence an organization, the so-called stakeholders, can improve the connections. This research is aimed to diagnose the relationship between the accommodation sector and stakeholders for the development of tourism in the locality. As specific objectives, aims to rank the level of importance of each stakeholder for the success of business and identify the ways of integrating lodging sector and stakeholders in the Vila do Abraão, at Ilha Grande. The work consisted of an exploratory study with qualitative and multiple case studies of accommodations in the Vila do Abraão, located at Ilha Grande, Rio de Janeiro, Brazil. Reviewed the literature on business management, taking the work of Freeman (1984) as its reference point. There were identified nine stakeholders that influence the management of lodging facilities. The groups identified have different levels of importance to business success, noting that customers and the media are stakeholders with greater influence. The existing relations of cooperation are scarce and lack of management projects to improve the connections with stakeholders.

Keywords: tourism; hospitality; stakeholders; lodging management. Ilha Grande.

\section{Resumen}

Verificar la participación de los alojamientos con los diversos grupos que influyen o pueden influir en una organización, llamados stakeholders, puede mejorar las conexiones. Esta investigación tiene por objeto el diagnóstico de la relación entre los alojamientos y los stakeholders para el desarrollo del turismo en la localidad. Como objetivos específicos, clasificar el nivel de importancia de cada uno para el éxito de los negocios y identificar las formas de integrar los alojamiento y los stakeholders en la Vila do Abraão, de Ilha Grande, Brasil. El trabajo consistió en un estudio exploratorio con tipos de estudios cualitativos y múltiples casos de alojamiento en la Vila do Abraão, ubicado en Ilha Grande, Río de Janeiro. Se realizó la revisión de la literatura sobre gestión empresarial, teniendo el trabajo de Freeman (1984) como punto de referencia. Se identificaron nueve stakeholders que influyen en la gestión de las instalaciones de alojamiento. Los grupos identificados tienen diferentes niveles de importancia para el éxito del negocio, teniendo en cuenta que los clientes y los medios de comunicación son actores con mayor influencia. Las relaciones de cooperación existentes son escasos y falta proyectos de gestión para mejorar las conexiones con stakeholders.

Palabras claves: turismo; hospitalidad; stakeholders; alojamientos. Ilha Grande.

\section{Introdução}

Nos diversos destinos turísticos que existem atualmente, é indissociável a presença dos meios de hospedagem. A simples necessidade de repousar em algum local e renovar as energias durante as viagens requer dos viajantes que utilizem estruturas para acomodação. $\mathrm{O}$ setor de 
hospedagem é muito importante para que o turismo como um todo se desenvolva, e, com as diversas necessidades e propósitos dos viajantes, existe uma diversidade de empreendimentos que se diferenciam em relação ao tamanho, à localização, ao tipo de público, à gestão, entre outros aspectos.

Para compreender a gestão específica dos diversos meios de hospedagem, a proposta desta pesquisa é ir além da caracterização e funcionamento de cada modelo e analisar de forma integrada o envolvimento com os diversos grupos que influenciam ou podem influenciar uma organização que, de acordo com Freeman (1984), são os chamados stakeholders. A habilidade de relacionar-se e integrar-se com os diferentes grupos que afetam direta ou indiretamente os negócios dos meios de hospedagem poderá representar um importante diferencial para se destacar no mercado cada vez mais diversificado e competitivo.

Resultado de dissertação de mestrado, este artigo tem como objetivo geral diagnosticar as relações dos meios de hospedagem com os stakeholders para o desenvolvimento turístico de uma localidade. Como objetivos específicos, propôs-se a hierarquizar o nível de importância de cada stakeholder para o sucesso dos negócios e identificar as formas de integração dos meios de hospedagem e os stakeholders na Vila do Abraão, Ilha Grande. Sendo assim, discutir-se-á a interação dos meios de hospedagem com os investidores, os colaboradores, a comunidade, os fornecedores, a concorrência, os clientes, os órgãos públicos e outros grupos para caracterizar a gestão a partir da rede de stakeholders que os cercam.

Compreender o funcionamento dos meios de hospedagem a partir da visão baseada nos stakeholders requer um prévio conhecimento bibliográfico das teorias e estudos já realizados a respeito da análise desses agentes. Para esse passo inicial da investigação, realizou-se pesquisa bibliográfica de caráter exploratório, que permitiu a consolidação do conhecimento em torno do tema, reunindo uma gama de informações e conceitos muito mais ampla do que apenas a pesquisa direta poderia fornecer. A pesquisa exploratória, de acordo com Gil (2008), tem como objetivo proporcionar maior familiaridade com o problema, para torná-lo mais explícito e constituir hipóteses. Pode-se dizer que essas leituras têm como objetivo principal ter e aprimorar ideias e intuições. 
Efetuou-se um intenso estudo bibliográfico a partir da leitura de escritos sobre a abordagem dos stakeholders produzidos por diversos pesquisadores das áreas de gestão empresarial (FREEMAN, 1984; CLARKSON, 1995; FREEMAN e MC VEA, 2001; DONALDSON e PRESTON, 1995; FROOMAN, 1999), estado da arte da teoria de stakeholders produzido no meio acadêmico brasileiro (CORADINI, SABINO e COSTA, 2010), de sistemas de turismo (BENI, 2007; LOHMANN e PANOSSO NETTO, 2008), cadeias produtivas (COSTA, 2005; SAMPAIO, 2005), análise estrutural do setor (PORTER, 1986, 1999), arranjos produtivos locais e sistemas de redes (COSTA e SOUTO-MAIOR, 2006; PRAHALAD, 2005; TINSLEY e LYNCH, 2008; GIBSON et al., 2005) para formular o referencial teórico e discutir os preceitos para análise dos casos.

A partir da formulação do referencial teórico, a investigação direcionou-se por verificar a relação dos meios de hospedagem com os stakeholders em uma localidade e, para desenvolver a averiguação decidiu-se pelo método de estudo de casos múltiplos, que de acordo com Eisenhardt (1989) "é uma estratégia de pesquisa que enfoca a compreensão da dinâmica presente dentro de uma única configuração", aplicado em cinco meios de hospedagem de categorias diferentes.

O local determinado para o estudo é a Ilha Grande, especificamente a Vila do Abraão, que evoluiu enquanto destino turístico com muitos conflitos, marcados pelo crescimento de fluxo de visitantes a partir do fechamento do presídio em 1994, pelas questões ambientais devido à existência de grande área de mata atlântica preservada e pelos aspectos socioculturais com as comunidades tradicionais e novos moradores que coexistem nesse território. Para obter dados específicos sobre a Ilha Grande, buscaram-se trabalhos de consultoria realizados para o local (MPE, 2004; PLANO DIRETOR, 1992) e pesquisas acadêmicas (MENDONÇA, 2008; MENDONÇA et al., 2008; PRADO, 2003a, 2003b; SAMPAIO, 2005) que auxiliaram a caracterizar e analisar a evolução do turismo e situação atual na ilha.

A metodologia possibilita verificar a aplicação prática e o diagnóstico de uma realidade, esperando contribuir para a consolidação da análise dos stakeholders na gestão de negócios em turismo e hospitalidade, assim como prover novos conhecimentos a gestão privada e ao desenvolvimento da Vila do Abraão. 


\section{Análise Baseada nos Stakeholders}

O termo stakeholder é encontrado em diversos textos, artigos e livros das mais diversas áreas. A utilização intensa do termo, entretanto, levanta questionamentos a respeito da sua origem, conceito, interpretação e utilidade. Tais preocupações levam a necessidade de uma discussão sobre o tema e a acompanhar a evolução de estudos concernentes à conceituação teórica e aplicações práticas na gestão estratégica de empresas.

Em vista disso, o artigo investiga o conceito, a partir de seu uso pioneiro pelos teóricos e pesquisadores de gestão estratégica, a evolução dos estudos e aplicações até a compreensão da gestão baseada nos stakeholders. Freeman (1984) com a obra Strategic Management: A Stakeholder Approach representa o marco referencial tanto dos estudos acadêmicos quanto das aplicações profissionais. A partir disso, verificam-se diversos autores que contribuíram para o aprimoramento da gestão das empresas focada na abordagem dos stakeholders (CLARKSON, 1995; DONALDSON e PRESTON, 1995; FROOMAN, 1999). O próprio Freeman, atualizando suas pesquisas e constatações sobre o mercado faz uma revisão de seu livro (FREEMAN e MC VEA, 2001), estende-se para comparações com a responsabilidade social das empresas (HARRISON e FREEMAN, 1999) e com a ética e a sustentabilidade (WHEELER, COLBERT e FREEMAN, 2003). Verifica-se que os autores referem-se à obra inicial de Freeman (1984), bem como às suas revisões e novas incorporações, e, em decorrência disso, verificar-se-á que a maioria das referências é baseada em Freeman (1984). O tema desenvolveu-se em diversas vertentes, agregando novas visões e contribuições, que incentivaram a edição de uma nova publicação por Freeman (2010), "Stakeholder Theory: the state of the art".

Alguns pesquisadores da área de turismo estabelecem relações com a análise dos stakeholders para desenvolver o planejamento turístico (SAUTTER e LEISEN, 1999; YILMAZ e GUNEL, 2009), formulação de estratégias em órgãos públicos municipais de turismo (COSTA, BOAVENTURA e BARRETO, 2010), analisar a dinâmica do mercado de turismo (MASSUKADO e BIZ, 2008), identificar as ações de cooperação dos eventos para os atores do entorno (KARLSEN e NORDSTROM, 2009) e até para criticar quando utilizado no 
planejamento do ecoturismo como instrumento econômico de incentivo à participação da população (FLETCHER, 2009).

\subsection{Afinal, quem são os stakeholders?}

Segundo Freeman (1984, p.vi $\left.{ }^{4}\right)$, "stakeholder is any group or individual who can affect, or is affected by, the achievement of a corporation's purpose". Nesse sentido, inclui tanto quem investe financeiramente na empresa quanto aquele que influencia de outras formas (fazendo um bom trabalho, por exemplo), ou que, simplesmente, sofre as consequências das ações organizacionais (como o grupo de moradores de uma região).

De acordo com essa definição, Teixeira e Domenico (2008) sintetizam que os stakeholders são entidades sociais - individuais ou coletivas - que têm algum tipo de influência capaz de afetar a realização dos objetivos da empresa. Nessa perspectiva, um gestor de um parque natural que aparentemente não influencia na receita gerada por um hotel de selva, por exemplo, poderá manifestar-se contra as atividades do hotel, caso estas interfiram na poluição e na degradação dos espaços naturais do parque. Sendo assim, os gestores dos hotéis e de todos os tipos de hospedagem devem levar em consideração os efeitos das suas ações sobre os stakeholders, bem como os efeitos recíprocos.

Dentro do elenco de entidades sociais que interferem ou podem interferir em um negócio, discutem-se critérios para conceituar e classificar os stakeholders para que cada organização verifique em quem e como deve depositar atenção como estratégia de desenvolvimento empresarial. Freeman (1984), visando organizar as discussões em função de razões práticas, categorizou os stakeholders entre aqueles que causam mudanças internas à empresa, tais como clientes, funcionários e sindicatos, investidores (ou financiadores, incluindo acionistas) e fornecedores, e outros grupos que geram mudanças no ambiente externo, mas que influenciam ou podem influenciar a empresa, tais como o governo, a concorrência, serviço de proteção ao consumidor e a comunidade de uma forma ampla. Por outro lado, Clarkson (1995, p.106) propõe a divisão entre stakeholders primários e secundários:

\footnotetext{
4 “qualquer grupo ou indivíduo que pode influenciar ou ser influenciado para a conquista dos objetivos de uma empresa” (FREEMAN,1984, p.vi)
} 
A primary stakeholder group is one without whose continuing participation the corporation cannot survive as a going concern. Primary stakeholder groups typically are comprised of shareholders and investors, employees, customers, and suppliers, together with what is defined as the public stakeholder group: the governments and communities that provide infrastructures and markets, whose laws and regulations must be obeyed, and to whom taxes and other obligations may be due. There is a high level of interdependence between the corporation and its primary stakeholder groups (CLARKSON, 1995, p.106 ${ }^{5}$ )

E, "secondary stakeholder groups are those who (..) are not engaged in transactions with the corporation and are not essential for its survival. The media and a wide range of special interest groups are considered as secondary stakeholders" (CLARKSON, 1995, p.1076)

\subsection{Contexto do (novo) panorama dos stakeholders}

Alguns gerentes têm dificuldade em separar mudanças importantes das triviais, em decidir onde uma resposta é necessária e onde medidas preventivas devem ser tomadas. Diante dessas mudanças e complexidade das atividades do mercado, as exigências feitas aos gerentes se tornaram maiores, cobrando-se respostas mais rápidas e eficientes.

As respostas das organizações a essas mudanças no ambiente têm sido tão variadas como as próprias mudanças. Freeman (1984, p.23) cita Ackoff (1974) e Post (1978), que argumentam que as organizações têm utilizado quatro modos básicos para lidar com uma evolução do ambiente externo. O primeiro modo, a inatividade, envolve ignorar as mudanças, e as atividades das empresas continuam como sempre. O segundo modo, reatividade, envolve esperar algo acontecer e responder a essa mudança; a resposta, então, é estimulada por uma

\footnotetext{
5 “Os stakeholders primários são aqueles grupos sem cuja participação e interesse contínuo, a empresa não poderia sobreviver. Esses grupos compreendem os acionistas e investidores, os empregados, os consumidores, os fornecedores, clientes e, ainda, os public stakeholders, isto é, o governo e a comunidade que provêm infraestrutura e mercado, que estabelecem e fazem cumprir as leis e regulamentações e a quem são devidos impostos e outras obrigações. Existe um alto nível de interdependência entre a organização e os stakeholders primários" (CLARKSON, 1995, p.106, tradução da autora).

6 “stakeholders secundários não estão envolvidos nas transações com as empresas nem são essenciais para a sobrevivência dela, mas podem se tornar críticos em situações específicas. A mídia e alguns grupos com interesses específicos fazem parte desse grupo" (CLARKSON, 1995, p.107, tradução da autora).
} 
força externa. O terceiro modo, pró-atividade, envolve a tentativa de prever as mudanças externas que ocorrerão e se posicionar diante dessas alterações antes do fato. O quarto modo para enfrentar as forças externas é o interativo, que consiste no envolvimento ativo com as mudanças e pressões que visam criar valor no futuro para todos os interessados.

Embora cada um desses modos de resposta seja apropriado para um conjunto de circunstâncias, todos eles pressupõem a existência de ideias para lidar com qualquer mudança externa e planejamento, mesmo no modo inativo.

Uma maneira de facilitar a gestão dessas mudanças é redesenhar o mapa, levando em conta todos os grupos ou indivíduos que afetam, podem afetar ou são afetados pela realização dos objetivos organizacionais. Cada um desses grupos tem um papel vital no sucesso dos negócios da empresa, por isso o modelo foi chamado de "Gestão dos Stakeholders". A figura 1 simplifica esse modelo, uma vez que cada grupo de interesse poderia ser dividido em várias outras categorias menores, pois nem todos os funcionários são iguais e os governos tampouco agem da mesma maneira.

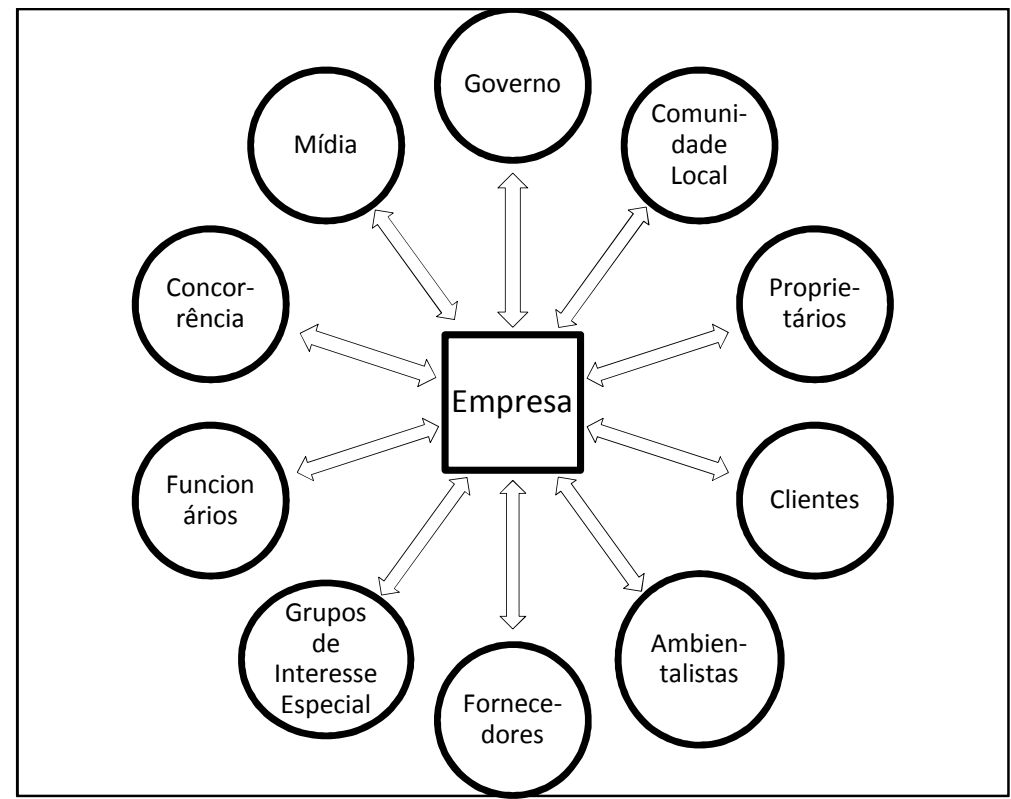

Figura 1 - Gestão dos stakeholders

Fonte: Freeman (1984, p.26, tradução da autora) 
Assumir um posicionamento perante as mudanças e compreender as diversas vertentes entre os grupos de influência demonstra as adaptações necessárias para a gestão das organizações. Faz-se necessário entender como começam as questões de cada stakeholder, qual a importância de tais ações e se serão revertidas em investimentos financeiros, seja para apoiar, seja para prejudicar a empresa.

Outra preocupação para uma correta gestão dos stakeholders é fazer a integração. Desenvolver conceitos e processos que deem abordagens integradas para lidar com múltiplos stakeholders em múltiplas questões. Para cada questão estratégica importante deve-se pensar nos seus efeitos sobre uma quantidade de stakeholders e, portanto, existe a necessidade de processos que ajudem a identificar as preocupações com esses grupos. Para cada um dos stakeholders considerados chaves, os gestores responsáveis pelo relacionamento com eles devem identificar as questões estratégicas que afetam esse grupo e elaborar, implementar e monitorar as estratégias para lidar.

\subsection{Auditoria dos stakeholders}

A fim de orientar a direção para a gestão de empresas, Freeman (1984) sugere uma metodologia nomeada de "Auditoria dos Stakeholders" que consiste em identificar os stakeholders e a sua força de influenciar os negócios em questão. Concorda com a análise situacional desenvolvida por Andrews (1965 apud FREEMAN, 1984) através da identificação dos pontos fortes e fracos, ameaças e oportunidades, e também com uma abordagem de análise de portfólio dos produtos, elaborada pelo Boston Consulting Group a fim de atingir uma composição balanceada dos produtos a partir da sua participação no mercado (share) e o crescimento do mercado, mas Freeman (1984) argumenta que essas ferramentas não são suficientes para abarcar os aspectos do ambiente de negócios por completo.

Os dois métodos de direcionamento do funcionamento da organização podem ser enriquecidos com uma melhor compreensão da relação com os stakeholders. Nesse sentido, a Auditoria dos Stakeholders soma à avaliação da empresa aspectos que mapeiam seu ambiente externo, incluindo os interesses dos stakeholders e as possibilidades de influenciar os rumos dela. O processo de Auditoria dos Stakeholders consiste em quatro principais tarefas estratégicas: indicar a missão corporativa, identificar interesses e preocupações dos 
stakeholders; avaliar estratégias empresariais para os stakeholders e adaptar prioridades conforme stakeholders. O desenvolvimento da auditoria não deve ocorrer de forma rígida, e ainda deve incluir alguns retornos do processo, mas serve como orientação para gestores entenderem o ambiente de acordo com as influências dos stakeholders (FREEMAN, 1984).

Para identificar quem são os stakeholders e suas preocupações para com o sucesso dos negócios, o pesquisador ensina a utilizar a Matriz Stakeholder/Sucesso da empresa, ilustrada abaixo, para facilitar na identificação da importância de cada grupo e também para que os gestores identifiquem prontamente quais grupos irão impactar na implementação dos objetivos específicos da empresa (FREEMAN, 1984).

Quadro 1 - Matriz Stakeholders/Sucesso nos negócios

\begin{tabular}{|c|c|c|c|c|}
\hline $\begin{array}{ll} & \text { Negócio } \\
\text { Stakeholder } & \end{array}$ & $\begin{array}{l}\varangle \\
: \\
0 \\
0 \\
0 \\
0 \\
0 \\
Z\end{array}$ & 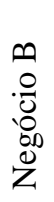 & $\begin{array}{l}\text { U } \\
.0 \\
0 \\
0 \\
0 \\
0 \\
z\end{array}$ & $\begin{array}{l}Z \\
Z \\
0 \\
0 \\
0 \\
0 \\
0 \\
z\end{array}$ \\
\hline Funcionários & 5 & 2 & 1 & 3 \\
\hline Associações & 5 & 2 & 1 & 4 \\
\hline Acionistas & 2 & 1 & 5 & 2 \\
\hline Governo & 1 & 5 & 5 & 1 \\
\hline Fornecedores & 3 & 5 & 1 & 3 \\
\hline Clientes & 1 & 1 & 5 & 1 \\
\hline Bancos & 0 & 1 & 3 & 2 \\
\hline Grupos Ativistas & 0 & 4 & 4 & 3 \\
\hline
\end{tabular}

Fonte: Freeman (1984, p.113)

Uma vez identificados e ordenados os stakeholders, segue-se listando as características e influências desses stakeholders. Com esse panorama, os gestores se tornam capazes de pontuar as principais preocupações e inquietações relacionadas aos stakeholders e principais aspectos a serem abordados nas estratégias direcionadas para qual(is) grupo(s) específico(s) (FREEMAN, 1984). 
As duas etapas anteriores serviram para formar uma perspectiva da situação externa da empresa, baseada nos stakeholders. A etapa 3 é para compreender como a empresa está indo ao encontro das necessidades dos stakeholders, ou seja, quais as estratégias existentes para gerenciar cada um ou grupo deles. Uma vez concluído isso, avaliar a efetividade de cada estratégia de relacionamento com cada stakeholder a partir de uma graduação que vai de pouco ou não efetiva a muito efetiva será fácil (FREEMAN, 1984).

Por fim, a quarta etapa é ajustar as prioridades estratégicas da organização a fim de atender melhor aos interesses dos stakeholders, buscando a satisfação dos relacionamentos ou, caso contrário, indica a necessidade de mudar o objetivo da empresa. Os gerentes que lidarão com o planejamento estratégico devem tomar essas decisões de mudanças, apesar de isso exigir um nível abstrato e complexo de gerência (FREEMAN, 1984).

Tomando esses procedimentos, Freeman (1984, p.116) conclui que, "ao realizar uma Auditoria dos Stakeholders, os gerentes podem agregar um bom entendimento de como efetivamente a empresa está cumprindo as exigências do mercado e do ambiente externo e cumprindo a missão declarada da empresa".

\section{Estudo de Casos Múltiplos}

Em virtude do delineamento geográfico adotado para o estudo - Vila do Abraão, consultaramse os dois maiores endereços eletrônicos ${ }^{7}$ que fazem a divulgação do destino Ilha Grande e de sua estrutura de apoio ao turismo.

Pela consulta, dividiram-se os meios de hospedagem em seis tipos diferentes, seguindo as categorias adotadas pelos sites:

- Campings: áreas com cozinha e banheiros coletivos, além dos espaços para lazer e montagem de barracas.

- Casas/Suíte: são casas mobiliadas e suítes (quarto e banheiro) equipadas que são alugadas para temporada.

\footnotetext{
${ }^{7}$ www.ilhagrande.org.br e www.ilhagrande.com.br <Acesso em 22 de abril de 2010>
} 
- Hostels: são estabelecimentos relativamente baratos com clima alegre e informal, ideal para pessoa sozinha, grupos ou para jovens que desejam fazer amizades.

- Pousadas Típicas: são hospedagens com simplicidade e aconchego onde o preço baixo é um bom diferencial (Diárias para casal variam de $\mathrm{R} \$ 70,00$ na baixa temporada a $\mathrm{R} \$$ 130,00 na alta). Algumas possuem localização na mata ou na subida das ruas.

- Pousadas Aconchegantes: são pousadas que possuem excelente atendimento e toda estrutura para os hóspedes que desejam contato direto com a natureza, oferecem bons serviços e boa localização com preços na média (Diárias para casal variam de $\mathrm{R} \$ 90,00$ na baixa temporada a $\mathrm{R} \$ 200,00$ na alta).

- Pousadas Prime: são pousadas com localização privilegiada, sofisticação e elegância, custo diferenciado, atendimento e serviços personalizados com total estrutura para os clientes (Diárias para casal variam de $R$ \$ 120,00 na baixa temporada a $R$ \$ 250,00 na alta).

Tabela 1 - Tipos e quantidades de meios de hospedagem na Vila do Abraão

\begin{tabular}{l|c}
\hline \multicolumn{1}{c|}{ Tipo de Meio de Hospedagem } & $\begin{array}{c}\text { Número de } \\
\text { Estabelecimentos }\end{array}$ \\
\hline Camping & 13 \\
Suíte/Casa & 22 \\
Hostel & 6 \\
Pousada Típica & 20 \\
Pousada Aconchegante & 42 \\
Pousada Prime & 19 \\
\hline & Total \\
\hline
\end{tabular}

Fonte: elaborado pela autora (2010)

A partir da compilação dos meios de hospedagem existentes na Vila do Abraão identificou-se 122 meios de hospedagem entre campings, Casas/Suítes, Hostels, Pousadas Típicas, Pousadas Aconchegantes e Pousadas Prime.

Para aprimorar os planos para a coleta de dados tanto em relação ao conteúdo dos dados quantos aos procedimentos que devem ser seguidos, desenvolveu-se o estudo de caso piloto, 
que de acordo com Yin (2005) é utilizado de uma maneira mais formativa, ajudando a desenvolver o alinhamento relevante das questões.

Aplicou-se um roteiro de entrevista estruturado, utilizando-se também um cartão com ilustração e conceito de stakeholder a fim de esclarecer a utilização do termo e obter uniformidade de sua aplicação junto ao entrevistado. Realizou-se gravação da entrevista, bem como levantamento dos dados do empreendimento a partir de roteiro estruturado de visita técnica. $\mathrm{O}$ estudo de caso piloto serviu para verificação dos instrumentos de pesquisa.

Uma vez testados os instrumentos de pesquisa, delimitou-se a aplicação de entrevistas com cinco gestores/proprietários de meios de hospedagem, identificando um gestor de cada tipo de meio de hospedagem existente na Vila do Abraão, com exceção dos estabelecimentos de camping, que não estão formalizados e tem um funcionamento inconstante. A partir desta escolha, buscou-se obter a visão e opiniões dos diferentes níveis de hospedagem que se encontram no destino, possibilitando a abrangência da análise sobre as relações com os stakeholders para cada segmentação.

\section{Relação dos Meios de Hospedagem com os Stakeholders na Vila do Abraão}

A partir das entrevistas junto aos gestores e representantes de alguns stakeholders, possibilitou-se avaliar as respostas a fim de diagnosticar as relações existentes entre os meios de hospedagem e os stakeholders na Vila do Abraão, Ilha Grande.

\subsection{Objetivos dos meios de hospedagem}

Quando analisados individualmente, verifica-se que os gestores dos negócios de hospedagem posicionam seus empreendimentos a fim de obter retornos financeiros, como qualquer outro negócio, mas refletem sobre o local, como se depreende dos objetivos colocados:

Quadro 2 - Objetivos dos empreendimentos entrevistados

\begin{tabular}{|l|l|}
\hline Pousada Prime & $\begin{array}{l}\text { "O primeiro objetivo é poder ganhar dinheiro para poder custear os } \\
\text { estudos dos filhos, pagar as contas". }\end{array}$ \\
\hline $\begin{array}{l}\text { Pousada } \\
\text { Aconchegante }\end{array}$ & $\begin{array}{l}\text { "Ganhar dinheiro, poder sobreviver, ter uma fonte de renda aqui no } \\
\text { Abraão, e como eu nasci aqui na Ilha, tenho muito cuidado com a }\end{array}$ \\
\hline
\end{tabular}




\begin{tabular}{|l|l|}
\hline & ecologia, natureza, a arquitetura da ilha". \\
\hline Pousada Típica & $\begin{array}{l}\text { "É um meio de negócio nosso. Só que a proposta é atender o turista } \\
\text { de forma diferente. A gente ainda não conseguiu atender esse } \\
\text { objetivo 100\%, mas estamos no caminho. A pousada é } \\
\text { ecologicamente correta". }\end{array}$ \\
\hline Suítes & $\begin{array}{l}\text { "Quando eu construí as suítes o intuito era atender bem o cliente, e, } \\
\text { em relação à Ilha Grande que ele desfrutasse de todas as belezas, } \\
\text { que ele gostasse da ilha e se sentisse bem na hospedagem". }\end{array}$ \\
\hline Hostel & $\begin{array}{l}\text { "Gerar recursos suficiente para viver e melhorar a estrutura } \\
\text { conforme os ideais dos sócios, além de preservar a natureza e } \\
\text { promover a visitação pelos pontos lindos da ilha". }\end{array}$ \\
\hline
\end{tabular}

\subsection{Existência de parcerias ou ações com os stakeholders}

No destino investigado, verificou-se de acordo com relatos dos entrevistados que a relação de conflitos é maior que a relação integrada entre os diversos meios de hospedagem existentes e destes com os stakeholders no local.

\section{Quadro 3 - Relações existentes}

\begin{tabular}{|l|l|}
\hline Pousada Prime & "Não tem parceria não. Realmente eu trabalho quase sozinho aqui”. \\
\hline $\begin{array}{l}\text { Pousada } \\
\text { Aconchegante }\end{array}$ & $\begin{array}{l}\text { "Existe muita desunião entre os pousadeiros. E aqui é assim, são } \\
\text { geralmente pousadas familiares, o dono mora na pousada, são pequenas. É } \\
\text { na base do salve-se quem puder. Não há políticas, não há acordos de } \\
\text { cavalheiros. Não há nada". }\end{array}$ \\
\hline $\begin{array}{l}\text { Pousada } \\
\text { Típica }\end{array}$ & $\begin{array}{l}\text { “(..) fraquíssima atuação que a Prefeitura tem sobre os meios de } \\
\text { hospedagem aqui no Abraão. Ela só atua quem é legalizado. O ilegal não } \\
\text { paga encargo social, consegue colocar a diária lá embaixo, mas a } \\
\text { Prefeitura não atua em cima deles". }\end{array}$ \\
\hline
\end{tabular}




\begin{tabular}{|l|l|}
\hline $\begin{array}{l}\text { Pousada } \\
\text { Aconchegante }\end{array}$ & $\begin{array}{l}\text { "A atuação da TurisAngra tem melhorado muito, mas decepcionou um } \\
\text { pouco agora que aconteceu o desastre, porque a gente esperava outra } \\
\text { atitude, mais forte, mais drástica. Porque inclusive eles disseram que iam } \\
\text { dar isenção de impostos, mas não deram". }\end{array}$ \\
\hline Pousada Prime & $\begin{array}{l}\text { "Tem muitas suítes na área do Governo, dizem que uns } 100 \text { quartos, que } \\
\text { não pagam impostos, é uma coisa de fundo de quintal, não tem } \\
\text { funcionários, a própria mulher cuida da casa. É uma concorrência muito } \\
\text { desleal. Cada um faz sua suíte e vai alugando". }\end{array}$ \\
\hline
\end{tabular}

Pela avaliação dos gestores de meios de hospedagem entrevistados, o legado de desunião é fortemente verificado pela concorrência fervorosa que se instalou no local, o desinteresse político de organização do território e suas atividades a partir dos órgãos públicos, a dificuldade de organizações não governamentais ou associações de grupos em estabelecer diretrizes comuns, a não formulação de parcerias e estratégias integradas com fornecedores e a falta de melhorias em trabalho conjunto com a comunidade, provendo retorno recíproco para o desenvolvimento qualitativo da prestação de serviços.

\subsection{Possibilidades para melhorar as relações}

Apesar das expectativas em relação às melhorias e ações integradas, ainda existe um sentimento de desunião nos negócios relacionados às atividades turísticas do destino.

Quadro 4 - Possibilidades para melhorias

\begin{tabular}{|l|l|}
\hline Suítes & $\begin{array}{l}\text { "Particularmente acho que a Ilha Grande é o destino mais barato do } \\
\text { Brasil. Acho que as pessoas deveriam valorizar o empreendimento, só eu } \\
\text { sei o duro que estou dando até hoje o pra conseguir fazer o negócio } \\
\text { funcionar". }\end{array}$ \\
\hline Hostel & $\begin{array}{l}\text { "Ainda tem muito a acontecer neste sentido das relações, seja entre nós } \\
\text { que oferecemos hospedagem, como as parcerias com outros negócios } \\
\text { aqui da vila, tipo: barcos, agências de mergulho, restaurante". }\end{array}$ \\
\hline Pousada Típica & $\begin{array}{l}\text { "Eu acho que deveria ter maior união entre as associações, de morador, } \\
\text { de pousadas, o comércio. Deveria ter mais união, mas as pessoas não } \\
\text { participam, daí fica mais difícil de reivindicar, sou um pouco pessimista, } \\
\text { cobrar dentro da Prefeitura. A união das pessoas sempre foi um problema }\end{array}$ \\
\hline
\end{tabular}




\begin{tabular}{|l|l|}
\hline & $\begin{array}{l}\text { aqui na ilha, as comunidades são muito diferentes. Tem pessoas que vem } \\
\text { de fora, porque gostam da ilha. Tem pessoas que vem de fora pra fazer } \\
\text { negócios, são comerciantes. Tem as comunidades de evangélicos, } \\
\text { fechados sobre eles. Tem a comunidade de ex-guardas que trabalharam } \\
\text { no presídio". }\end{array}$ \\
\hline Pousada Prime & $\begin{array}{l}\text { "A única forma que eu vejo pra resolver isso é ter uma autoridade } \\
\text { externa, incontestável, é assim e pronto. Achar uma direção pra que tipo } \\
\text { de turismo queremos na ilha, e depois estabelecer as regras, e seguir essa } \\
\text { direção e não desviar o caminho. E nem pode ser uma autoridade de } \\
\text { Angra, da prefeitura também não". }\end{array}$ \\
\hline
\end{tabular}

A verificação desse cenário, a partir das entrevistas, é o início para a análise da estrutura comercial formada pelos meios de hospedagem e outros empreendimentos de apoio ao turismo. O quadro negativo que se estabelece na destinação coloca em risco os investimentos financeiros, mas, além disso, agrava as ameaças de conservação do ambiente natural e possibilidade de degradação da cultura e dos valores sociais ali mantidos.

\subsection{Fórum do trade turístico}

Identificou-se uma iniciativa importante em prol do desenvolvimento integrado e participativo dos diversos atores envolvidos com a atividade turística na Ilha Grande: o Fórum do Trade Turístico, que é encontro organizado nas instalações do Jornal O ECO. De acordo com o idealizador do Jornal e do Fórum, Nelson Palma (2010):

Aqui eles deveriam formar um todo, para que ganhassem força. Eu organizo a reunião do trade, mas é pouco, acontece uma vez por mês e só. Se as discussões fossem feitas de forma conjunta, busca pelas soluções, o objetivo comum, daria mais certo. Mas os meios de hospedagem daqui não trabalham assim. O Fórum é aberto para todo mundo do trade turístico.

Ações como o Fórum do Trade Turístico, apesar de representar a consolidação de um espaço de discussão e integração em torno de um objetivo comum, ainda se encontra como iniciativa isolada. Entretanto, os poucos participantes demonstram interesse em melhorar o destino como um todo, e tendo como consequência, resultados positivos para seus negócios. 


\section{Identificação e Hierarquização dos Stakeholders na Visão dos Meios de Hospedagem}

Baseado na metodologia proposta por Freeman (1984) de se identificar e diagnosticar as relações com os stakeholders através da Auditoria dos Stakeholders elaborou-se a entrevista com perguntas que possibilitassem a identificação, por parte dos gestores, dos diversos grupos que influenciam o seu meio de hospedagem. Foram identificados nove stakeholders que influenciam os seus negócios.

Os gestores também foram questionados a determinar o nível de importância atribuído a cada stakeholder, a partir de uma escala, sendo: 5 "Extremamente importante" para o sucesso de seu empreendimento; 3 "Importante" para o sucesso de seu empreendimento; 1 "Pouco importante" para o sucesso de seu empreendimento; 0 Não identificou como um stakeholder neste empreendimento.

A partir da análise das respostas, chegou-se à Matriz Stakeholders/Sucesso nos negócios de hospedagem na Vila do Abraão.

Quadro 5 - Matriz stakeholder/sucesso dos negócios de hospedagem 


\begin{tabular}{|c|c|c|c|c|c|}
\hline & $\stackrel{\mathscr{Z}}{\dddot{Z}}$ & 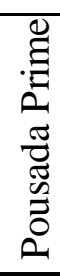 & 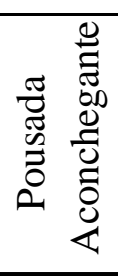 & 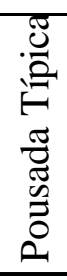 & $\begin{array}{l}\bar{D} \\
\tilde{D} \\
0 \\
0\end{array}$ \\
\hline Investidores & 0 & 5 & 3 & 0 & 0 \\
\hline Clientes & 5 & 5 & 5 & 5 & 5 \\
\hline Fornecedores & 5 & 1 & 5 & 3 & 3 \\
\hline ONGs & 0 & 1 & 1 & 1 & 1 \\
\hline TurisAngra & 1 & 1 & 3 & 3 & 1 \\
\hline Concorrência & 1 & 5 & 5 & 5 & 5 \\
\hline Comunidade & 5 & 1 & 3 & 3 & 5 \\
\hline Funcionários & 5 & 3 & 3 & 5 & 3 \\
\hline Mídia & 5 & 5 & 5 & 5 & 5 \\
\hline
\end{tabular}

Fonte: elaborado pela autora (2010)

Visualizando-se a Matriz identifica-se individualmente o nível de importância de cada stakeholder em relação ao sucesso dos negócios de cada meio de hospedagem analisado. Fazendo uma somatória, formatou-se a hierarquia quanto ao nível de importância na relação com os empreendimentos.

Apurando os níveis de importância dado a cada stakeholder, detectou-se uma hierarquia nas relações entre cada stakeholder e os meios de hospedagem. A figura abaixo ilustra os diversos stakeholders e o tamanho do círculo simboliza a força da importância para o sucesso das atividades de hospedagem na Vila do Abraão. 


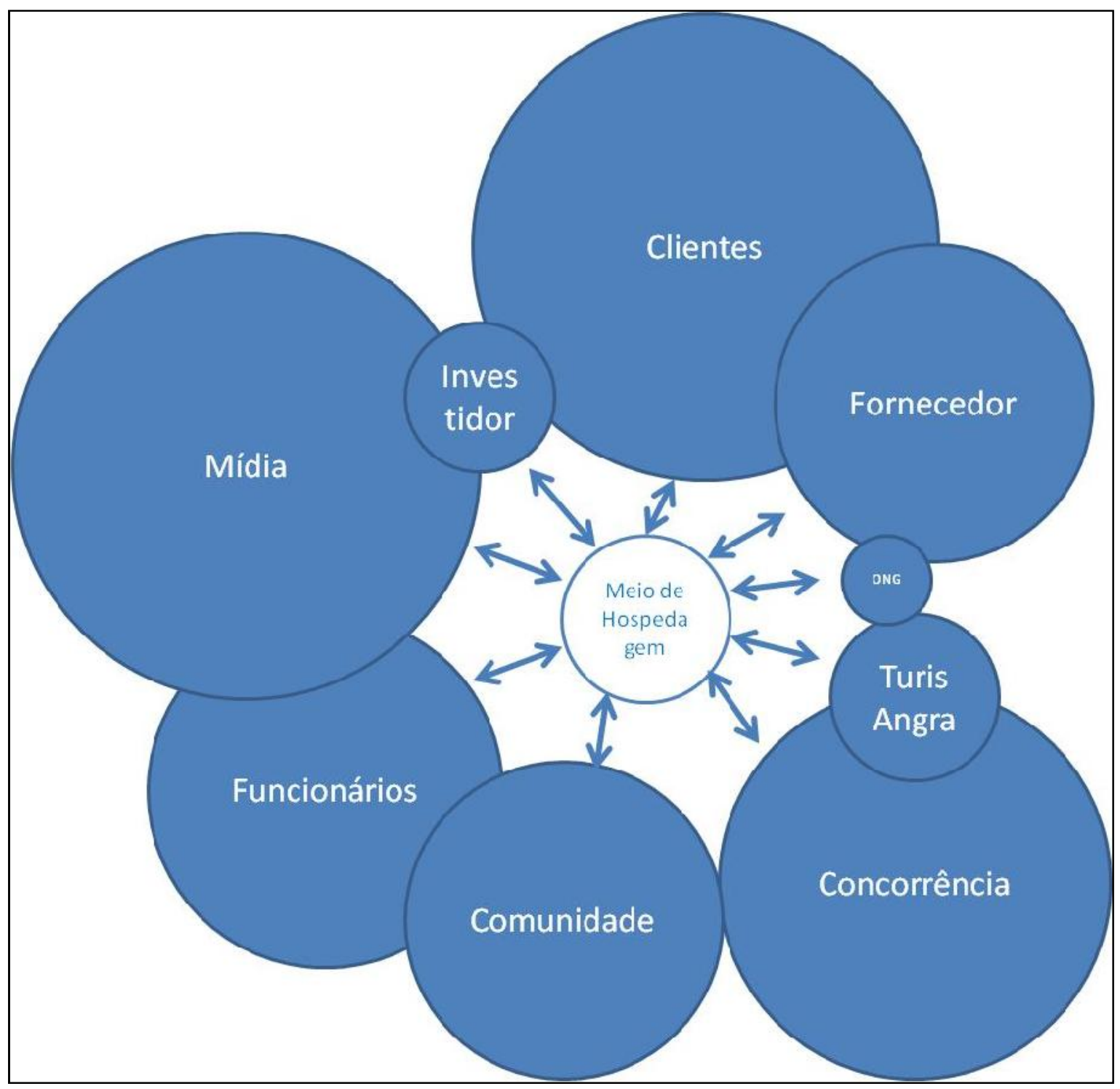

Figura 2 - Hierarquia dos stakeholders

Fonte: elaborado pela autora (2010)

A interpretação das respostas a respeito do nível de importância dos diversos stakeholders possibilitou identificar a relação com os diversos grupos, perante a identificação de suas influências para o sucesso dos negócios. 


\subsection{Investidores e Financiadores}

Em 100\% dos casos entrevistados, os próprios proprietários são os únicos investidores de seus negócios.

Já em relação aos Financiadores, verificaram-se respostas diferenciadas entre os diversos meios de hospedagem entrevistados.

Alguns o identificam como grupo extremamente importante e essencial para o sucesso dos negócios, uma vez que são feitos empréstimos anualmente para sustentação financeira do empreendimento, durante a baixa temporada. A resposta do proprietário da Pousada Prime explicita esta relação: "Os bancos interagem sempre comigo. Todo ano eu pego empréstimo no banco para passar a baixa temporada. São extremamente importantes".

Essa dependência varia, para outra empresária, de acordo com a produtividade da alta temporada, demonstrando que a relação com financiadores tem forte dependência com o fator de sazonalidade:

Agora com o deslizamento, tivemos um verão fraquíssimo, e estamos todos passando por uma situação grave, porque durante o verão é que fazemos a economia para que a gente pague as contas na baixa temporada. Então agora, vou ter que ir ao banco fazer empréstimo para pagar as contas. Quando o verão é bom, não precisamos dos bancos, mas como foi ruim, precisamos recorrer a empréstimos (Proprietária Pousada Aconchegante, 2010).

\subsection{Clientes}

Já os clientes foram considerados com unanimidade entre os entrevistados como um stakeholder extremamente importante para o sucesso dos negócios. De fato, os meios de hospedagem dependem diretamente das decisões dos turistas que visitam a Ilha Grande em ter uma boa ocupação. A relação envolve, pelas respostas obtidas, que o valor da diária é um dos principais fatores para a decisão do visitante, entretanto alguns empreendimentos demonstraram preocupação com o diferencial a ser oferecido para os hóspedes relacionados à infraestrutura, preocupação com requisitos ambientais e práticas sustentáveis.

O gestor da Pousada Típica, por exemplo, relata suas preocupações para atrair os hóspedes pelo diferencial relacionado às práticas ambientais: "A gente colocou tratamento de água na piscina, luz com iluminação eletrônica, aquecedor solar, ar condicionado mais econômico, 
que ajudou a diminuir os gastos. (...) Lavamos a roupa de cama e de banho com um bactericida, que a vigilância exigiu da gente. A roupa de cama fica lacrada, a roupa de banho também. É feito a desinfecção".

\subsection{Fornecedores}

Os fornecedores formam um grupo que engloba desde os mercados provedores de artigos para café da manhã, material de limpeza, bebidas etc., como também agências de passeios de barco, guias de turismo, serviços de transfer, e ainda, agências de turismo emissivo localizados fora da Ilha Grande, que auxiliam os viajantes na organização de suas viagens para o destino. Quando questionados sobre o nível de importância deste stakeholder aos entrevistados, detectou-se que foram avaliados como extremamente importante para o sucesso de seus negócios para aumentar serviços e facilidades aos seus hóspedes, no caso do gestor da Suíte; já o gestor da Pousada Prime argumentou que é pouco importante, porque facilmente poderia trocá-los, uma vez que não oferecem nenhuma vantagem em relação a outro; a Pousada Aconchegante indicou que são extremamente importantes, porque dependem dos mercados, no caso, para definir a qualidade de alguns serviços seus, tais como o que servir no café da manhã; a Pousada Típica acha muito importante, mas não utiliza os fornecedores de mercadoria da Vila, pois busca qualidade e preço bom, tendo que comprar no Rio de Janeiro e trazer frutas, frios, bebidas para o consumo da pousada; e por fim, o Hostel não depende dos fornecedores por não oferecer café da manhã e serviços adicionais.

\subsection{Organizações não governamentais}

Quando questionados a respeito das ONGs enquanto stakeholder que influencia ou é influenciado pelos empreendimentos de acomodação, os gestores indagaram a respeito e não conseguiram responder de imediato. Após uma reflexão, apesar da Pousada Prime fazer parte da AMHIG, respondeu que é uma instituição pouco importante para o negócio e nada contribui para o sucesso de suas atividades. O gestor da Pousada Típica diz ter uma parceria com a Associação dos funcionários do Banco do Brasil para divulgar seu negócio em troca de descontos para os associados, entretanto a ação tem tido pouco retorno para seu negócio. 


\section{5. Órgãos públicos}

Sobre os órgãos públicos, os entrevistados destacaram em suas respostas a TurisAngra, que é a instituição municipal responsável pela organização do turismo. As respostas foram de que é um organismo pouco importante e que deveria ser mais atuante para o sucesso dos negócios de hospedagem, entretanto as experiências dos entrevistados com a instituição é de nenhuma ou pouca atitude em prol do desenvolvimento turístico da Ilha Grande.

Pelo contrário, de acordo com relato do entrevistado da Pousada Prime, "a TurisAngra coloca pessoas incompetentes para trabalhar conosco. Uma vez vieram participar de uma reunião e deram à ideia de colocar um teleférico para subir até o Pico do Papagaio. Acho que viram isso na Europa ou outro lugar e acharam que aqui poderiam fazer igual."

A gestora da Pousada Aconchegante informou que a TurisAngra demonstrou apoio no momento logo após o desastre do Ano Novo, em que as chuvas provocaram desmoronamentos na Vila do Bananal, prometendo dar isenção ou redução de impostos para os meios de hospedagem, que foram diretamente afetados pelos cancelamentos de hóspedes, e na verdade, o que ocorreu foi a cobrança normal do IPTU e ainda tiveram que contribuir com novo imposto, chamado de solidariedade para a recuperação de Angra dos Reis.

Tal insatisfação é generalizada sobre a Subprefeitura de Angra dos Reis, que na opinião dos entrevistados nada faz e ainda se isenta de algumas propostas não cumpridas.

\subsection{Concorrência}

O stakeholder concorrência quando questionado sobre o nível de importância para o sucesso do negócio gerou respostas negativas e críticas. Para as pousadas, os gestores consideraram que a concorrência é extremamente importante para seu sucesso e apenas para o gestor das Suítes considerou nada importante.

Os gestores de pousadas alegaram que a disputa pelos turistas para as hospedagens "é uma coisa séria”, principalmente em torno do baixo valor das diárias praticadas, incorrendo com a diminuição da qualidade e desvalorização do segmento como um todo. A concorrência se torna ainda desleal perante a ilegalidade de algumas acomodações que são oferecidas nas próprias casas de alguns moradores. Tal alternativa não é feito de forma organizada, nem de 
acordo com as determinações legais para instalar um meio de hospedagem, mesmo que familiar.

\subsection{Comunidade}

O próximo stakeholder questionado aos gestores dos meios de hospedagem foi a comunidade. Para o Gestor das Suítes, a comunidade é extremamente importante para o sucesso de seu negócio, explicando que seus vizinhos que também alugam suítes formam uma rede de indicações, uma vez que tem poucas unidades habitacionais, facilmente ficam lotados e passam a indicar as suítes dos vizinhos. É interessante notar que tal iniciativa ocorre porque além de serem gestores de um negócio, as pessoas mantêm relações de amizade dentro da comunidade.

Já os gestores de pousadas identificaram a comunidade como importante ou pouco importante para o sucesso de seus negócios. O gestor da Pousada Prime identificou a comunidade como mão de obra e a caracterizou como de baixa qualificação e de difícil contratação, pois também não se empenham em melhorar suas condições de vida através do trabalho. E, a gestora da Pousada Aconchegante identificou também que a comunidade que não trabalha com as atividades turísticas não gosta do turismo e acaba tratando mal os visitantes da vila.

\subsection{Funcionários}

Os funcionários são stakeholders considerados importante ou extremamente importantes para o sucesso dos meios de hospedagem. Apesar de suas atribuições serem essenciais para o funcionamento dos negócios, a baixa qualificação, o desconhecimento de idiomas estrangeiros, a falta de formação acadêmica, o desinteresse em construir carreiras foram apontados pelos entrevistados como problemas para a boa relação com este stakeholder. Conforme trecho da entrevista da gestora da Pousada Aconchegante (2010):

Aqui é muito difícil, não dá pra fazer seleção, um anúncio, você quebra um galho, coloca qualquer um. E aqui na pousada isso se agrava, porque você colocar nos quartos dos hóspedes que tem dinheiro, pertences caros. Outra coisa é formação, eu não tenho ninguém que fala inglês, nem camareira, nem na recepção. Daí, você vai quebrando um galho. Tudo na base do improviso. 


\subsection{Mídia}

E, por fim, a mídia foi identificada como stakeholder extremamente importante para o sucesso dos meios de hospedagem. Indicam, de um lado, a contribuição para a divulgação dos seus empreendimentos para os turistas e, por outro, ressaltam o poder deste stakeholder em prejudicar os seus negócios, como o que ocorreu após os deslizamentos do Ano Novo, que afetou a praia do Bananal, mas a repercussão da notícia através da mídia impactou diretamente na drástica redução de visitantes à Vila do Abraão, que nada foi afetada pelas chuvas.

\section{Considerações Finais}

A análise baseada na abordagem dos stakeholders se mostrou ferramenta muito efetiva para o planejamento e organização do turismo e análise da gestão dos meios de hospedagem. Verificar os diversos grupos que influenciam e são influenciados por uma determinada atividade, o segmento de hospedagem, no caso do estudo em tela, ou sob qualquer outro aspecto, dá uma diretriz que possibilita uma ampla e detalhada compreensão do estudo. Nesse sentido, verificou-se a efetividade da abordagem em relação a: identificação dos grupos que tenham algum tipo de relação com o foco da análise; levantamento dos stakeholders, independente da relação positiva ou negativa, que mantém junto ao objeto analisado; hierarquização dos stakeholders quanto à importância da relação para o sucesso da atividade fim do negócio; e priorização nas estratégias de relacionamento de acordo com a hierarquia levantada.

O estudo de casos múltiplos permitiu a aplicação de ferramentas desenvolvidas pela gestão dos stakeholders na análise da gestão dos meios de hospedagem em busca de iniciativas de cooperação entre os empreendimentos em prol da sustentabilidade e maior competitividade do local pesquisado, a Vila do Abraão.

Por estarem localizados em uma ilha, os meios de hospedagem têm um funcionamento que depende necessariamente de muitos fatores externos que vão além do pleno controle da gerência. Esse aspecto influencia diretamente na necessidade mútua e dependência das pessoas em relação ao próximo, e isto se reflete nos negócios também. Os fornecedores, por 
exemplo, foram considerado stakeholders de grande importância para os empreendimentos, uma vez que estes dependem de mercadorias vendidas e serviços prestados para satisfazer seus clientes com qualidade e diferencial. Por essa ótica, vislumbra-se que iniciativas que fomentem fornecimento de produtos e serviços com qualidade e preços competitivos, poderão conseguir, como consequência, o aumento da fidelidade e das compras por parte dos meios de hospedagem.

A união e a centralização das compras de suprimentos entre os meios de hospedagem poderiam criar uma força de negociação junto aos fornecedores para atingir melhores produtos/serviços, além de permitir melhor negociação em relação a formas de pagamento mais adequadas, barganha por melhores preços e até a possibilidade de entrega diretamente na ilha, reduzindo os custos com frete e transporte de material. Iniciativas nesse sentido voltamse para a redução de custos e melhoria da qualidade dos meios de hospedagem e não diretamente na geração de mais receita. E, a partir das respostas obtidas nas entrevistas, seriam ações que teriam grande adesão por parte dos gestores, que veem com viés a divisão de receita, seja através de repasse de comissão ou concessão de descontos.

A partir de ações mais focadas na redução de custos e a melhoria da qualidade atingindo níveis de eficiência positiva, a credibilidade da organização e do funcionamento cooperado entre os meios de hospedagem permitiria, a partir desse momento, incentivar outras práticas conjuntas de promoção, canal de distribuição, políticas tarifárias, etc. Ou seja, ações que afetem a captação de clientes e divisão de receitas.

Dando continuidade à pesquisa, almeja-se colaborar com os estudos de desenvolvimento turístico dos destinos a partir de uma melhor gestão do relacionamento dos meios de hospedagem com os diversos stakeholders, consolidando, assim, a importância das movimentações cooperativas e parcerias entre os diversos grupos que atuam em uma mesma destinação e que vislumbram de forma compartilhada melhor competitividade e sustentabilidade. Dessa maneira, espera-se que estratégias mais bem planejadas dos meios de hospedagem em prol de interesses comuns em relação à localidade demonstrem o comprometimento e responsabilidade dos empreendedores locais em prol de uma repercussão do desenvolvimento em nível mais amplo. 
Aprofundar-se em teorias das áreas de conhecimento correlatas, como a administração, traz, com a análise baseada nos stakeholders, uma importante contribuição para a interconexão com o turismo e a hospitalidade. Através do estudo de casos múltiplos realizado na Ilha Grande, fez-se o diagnóstico de uma realidade tendo em vista contribuir para a consolidação da análise dos stakeholders na gestão de negócios em turismo e hospitalidade, assim como prover novos conhecimentos à gestão privada e ao desenvolvimento comunitário na Vila do Abraão.

Diante do exposto, verifica-se possibilidades de aplicação da abordagem dos stakeholders para além do empregado no estudo atual, vislumbrando algumas sugestões para outras pesquisas, tais como: análise dos stakeholders para o planejamento do destino turístico; análise dos stakeholders para elaboração de políticas públicas do turismo; análise dos stakeholders e a hospitalidade de uma destinação; etc.

Por fim, pesquisas da hospitalidade apontam uma diversidade de possibilidades de estudo acerca das conexões entre indivíduos, empreendimentos, organizações, grupos de indivíduos e de empreendimentos que, organizados de forma integrada, bem articulada e objetivando um futuro comum à sustentabilidade, proporcionarão o alcance de um posicionamento competitivo no mercado e coerente com o desenvolvimento comunitário de todos os envolvidos. O presente artigo agrega forças ao desafio proeminente do desenvolvimento sustentável dos destinos, inspirando novos encaminhamentos para o alcance dessa aspiração.

\section{Referências}

ARAÚJO, S. M. Artifício e autenticidade: o turismo como experiência antropológica. In: DIEGUES, Antonio Carlos (Org.). Ilhas e sociedades insulares, 1997.

BENI, M. Análise estrutural do turismo. São Paulo: SENAC, 2007.

CLARKSON, M. B. E. A stakeholder framework for analyzing and evaluating corporation. Academy of Management Review. v.20, n.1; p. 92-117, 1995.

COOPER, C.; FLETCHER, J.; FYALL, A; GILBERT, D.; WANHILL, S. Turismo: princípios $e$ práticas. Porto Alegre: Bookman, 2007.

CORADINI, C.; SABINO, M. S; COSTA, B. K. Teoria dos stakeholders: estado da arte produzido no Brasil. In: Seminários em Administração - SEMEAD, 8, 2010, São Paulo. 
COSTA, B. K.; BOAVENTURA, J. M. G.; BARRETO, L. M. T. Formulação de estratégias no turismo: um estudo em órgãos municipais no Estado de São Paulo. Turismo em Análise, v. 21, n. 1, p. 110-129, abril 2010.

COSTA, H. Análise de relações de rede do perfil de competitividade turística: estudo comparativo entre São Francisco do Sul e Laguna - SC. Dissertação de mestrado. Vale do Itajaí, UNIVALI, 2005.

COSTA, H. e SOUTO-MAIOR, A. Sistemas produtivos locais em turismo: relacionamentos estratégicos e aglomeração territorial como vantagens competitivas. Observatório de Inovação no Turismo - Revista Acadêmica, v.1, n.1, p.1-22, 2006.

DENCKER, A.; DA VIA, S. Pesquisa empírica em Ciências Humanas. São Paulo: Futura, 2002.

DIEGUES, A. C. (Org.). Ilhas e sociedades insulares. São Paulo: NUPAUB: CEMAR: USP, 1997.

DOMENICO, S.M.R.De. Valores relativos à competição organizacional e interações entre stakeholders. Tese de doutorado. Programa de Pós Graduação em Administração de Empresas. São Paulo, Universidade Presbiteriana Mackenzie, 2007.

DONALDSON, T.; PRESTON, L. E. The stakeholder theory of the corporation: concepts, evidence and implications. Academy of Management Review. v.20, n.1, p.65-91, 1995.

DUNHAN, L.; FREEMAN, R.E.; LIEDTKA, J. Enhancing stakeholder practice: a particularized exploration of community. Business Ethics Quarterly, v.16, n.1, p.23-42, 2006.

EISENHARDT, K. Building theories from case study research. The Academy of Management Review, Vol. 14, No. 4, pp. 532-550, 1989.

FLETCHER, R. Ecotourism discourse: challenging the stakeholders theory. In: Journal of Ecotourism. V. 8, N. 3, p. 269-285, 2009.

FREEMAN, R. E. Strategic Management: a stakeholder approach. Minnesota: Pitman, 1984.

The politics of stakeholder theory: some future directions. Business Ethic Quarterly, v.4, n.4, p.409-421, 1994.

FREEMAN, R.E.; MC VEA, J. A stakeholder approach to Strategic Management. Darden Graduate School of Business Administration. Working Paper No. 01-02, 2001.

FREEMAN, R. E; HARRISON, J. S.: WICKS, A. C.; PARMAR, B.; COLLE, S. Stakeholder theory: the state of the art. Cambridge: Cambridge University Press, 2010.

FROOMAN, J. Stakeholder influences strategies. Academy Management Review, vol. 24, n. 2, p. 191205, 1999.

GIBSON, L; LYNCH, P.; MORRISON, A. The Local Destination Tourism Network: Development Issues. Tourism and Hospitality Planning \& Development, v.2, n.2, p.87-99, ago. 2005.

GIL, A. C. Métodos e técnicas de pesquisa social. São Paulo: Atlas, 2008.

IRVING, M. (Org.) Áreas protegidas e inclusão social: construindo novos significados. Rio de Janeiro: Aquarius, 2006.

HARRISON, J.S.; FREEMAN, R.E. Stakeholders, social responsibility and performance: empirical evidence and theoretical perspectives. Academy of Management Journal. V.42, n.5, p.479-485, 1999.

KARLSEN, S.; NORDSTRÖM, C.S. Festivals in the Barents Region: Exploring Festival-stakeholder Cooperation. Scandinavian Journal of Hospitality and Tourism, V.9, Nos. 2-3, p.130-145, 2009. 
LASHLEY, Conrad e MORRISON, Alison (Orgs.) Em busca da hospitalidade: perspectivas para um mundo globalizado. Barueri: Manole, 2004.

LOHMANN, G. e PANOSSO NETTO, A. Teoria do turismo: conceitos, modelos e sistemas. São Paulo: Aleph, 2008.

MASSUKADO, M. S; BIZ, A. A. Planejamento e gestão de destinos turísticos: colaboração e parcerias sob a ótica dos stakeholders. Trabalho apresentado no $V$ Seminário da Associação Nacional de Pesquisa e Pós-Graduação em Turismo - Belo Horizonte, MG - 25 e 26 de agosto de 2008.

MPE. Ilha Grande (RJ): Análise de sua visitação e propostas para seu ordenamento. FUNBIO: 2002.

MENDONÇA, T. C. O turismo que se tem e o turismo que se quer: discurso e significados a propósito do turismo na Vila do Abraão - Ilha Grande (Angra dos Reis, RJ). Trabalho apresentado ao "GT - 10 Turismo, antropologia e inovação" do V Seminário de Pesquisa em Turismo do MERCOSUL - Caxias do Sul, 27 e 28 de julho de 2008a.

MENDONÇA, T.; HACON, V.; MORAES, E.; FAICO,G.; IRVING,M.; FERNANDES, L.; SANCHO,A.; FASANO,R. Parque Estadual da Ilha Grande \& Parque Estadual Marinho do Aventureiro: interpretando caminhos possíveis para uma gestão inovadora do "paraíso" Ilha Grande. In: Parques Estaduais do Rio de Janeiro: construindo novas práticas para a gestão. São Carlos: RiMA, 2008 b.

OLAVE, M. E.; AMATO NETO, J. Redes de cooperação produtiva: uma estratégia de competitividade e sobrevivência para pequenas e médias empresas. In: Gestão \& Produção, v.8, n.3, p.289-303, dez. 2001, São Paulo, 2001.

PORTER, M. Estratégia competitiva: técnicas para análise de indústrias e da concorrência. Rio de Janeiro: Campus, 1986.

Competição: estratégias competitivas essenciais. Rio de Janeiro: Campus, 1999.

PRADO, R. M. As espécies somos nós: reflexão a propósito do ecoturismo na Ilha Grande. In: Horizontes Antropológicos, Porto Alegre, ano 9, n. 20, p. 205-224, outubro de 2003

Tensão no paraíso: aspectos da intensificação do turismo na Ilha Grande. In: Caderno Virtual do Turismo, n. 7. Rio de Janeiro: Instituto Virtual do Turismo/COPPE/UFRJ, 2003.

PRAHALAD, C.K. A riqueza na base da pirâmide. Porto Alegre: Bookman, 2005.

SAMPAIO, R. Estratégias para a superação de problemas locais à Vila do Abraão e sua relação com o desenvolvimento sustentável do turismo. Dissertação de mestrado. Rio de Janeiro, Departamento de Administração Pública e de Empresas, Fundação Getúlio Vargas, 2005.

SAUTTER, T. E.; LEISEN, B. Managing stakeholders: a tourism planning model. Annals of Tourism Research. V. 26, n. 2, p. 312-328, 1999.

TEIXEIRA, M. L. M; DOMENICO, S. M. R. De. Fator Humano: uma visão baseada em stakeholders. In: HANASHIRO, D. M. M.; TEIXEIRA, M. L. M.; ZACCARELLI, L. M. (Orgs.) Gestão do Fator Humano: uma visão baseada em stakeholders. São Paulo: Saraiva, 2008.

TINSLEY, R e LYNCH, P. Differentiation and tourism destination development: Small business success in a close-knit community. Tourism and Hospitality Research, v.8, n.3, p.161-177, 2008.

UFRJ. Plano Diretor do Parque Estadual da Ilha Grande. Rio de Janeiro, Universidade Federal Rural (RJ), IEF-RJ, Pró-Natura, 1992. 
WADA, E. Reflexões de uma aprendiz da hospitalidade. In: DENCKER, A.; BUENO, M. (Orgs.) Hospitalidade: cenários e oportunidades. São Paulo: Thomsom, 2003.

WEARING, S.; NEIL, J. Ecoturismo: impactos, potencialidades e possibilidades. Tradução Carlos David Szlak. Barueri: Manole, 2001.

WHEELER, D, COLBERT, B, FREEMAN R. Focusing on Value: Reconciling Corporate Social Responsibility, Sustainability and a Stakeholder Approach in a Network World. Journal of General Management, vol. 28, n.3, p.1-28, 2003.

WUNDER, S. Big island, green forests and backpackers: Land-use and development options on Ilha Grande. Rio de Janeiro, Brazil and Copenhagen, Centre for Development Research, 2000.

YILMAZ, B.S.; GUNEL, O.D. The importance of strategic stakeholder management in tourism sector: research on probable applications. Tourismos: an International Multidisciplinary Journal of Touris, vol.4, n.1, p.97-108, 2009.

YIN, R. K. Estudo de caso: planejamento e métodos. Porto Alegre: Bookman, 2005.

\section{Recebido em: 17/04/2011 (1 ${ }^{\mathrm{a}}$ versão $)$ - 18/07/2011 ( (2 versão)}

Aprovado em: 16/11/2011 